Supporting information for

\title{
Exploration of the Hysteresis in Speciated Emissions during Transient Gasoline Engine Combustion
}

David Wilson, Dylan Lehmier, Casey Allen

Department of Mechanical Engineering, Marquette University, Milwaukee, Wisconsin 53233, USA

\begin{tabular}{|c|c|c|c|}
\hline Species & $\begin{array}{c}\text { Inlet Composition } \\
\text { Process Noise Variance } \\
\quad\left(R_{w w, Z i n}\right)\left(\mathrm{PPM}^{2}\right)\end{array}$ & $\begin{array}{c}\text { Measurement Noise } \\
\text { Variance } \\
\left(R_{v v, Z c e l l}\right)\left(\mathrm{PPM}^{2}\right)\end{array}$ & $\begin{array}{l}\text { Centerburst Weight } \\
(c)\end{array}$ \\
\hline 1,3 butadiene $\left(\mathrm{C}_{4} \mathrm{H}_{6}\right)$ & 5.00 & 4.60 & 0.99 \\
\hline Acetylene $\left(\mathrm{C}_{2} \mathrm{H}_{2}\right)$ & 63.50 & 1.48 & 0.74 \\
\hline Benzene $\left(\mathrm{C}_{6} \mathrm{H}_{6}\right)$ & 5.00 & 78.52 & 0.97 \\
\hline Cyclohexane $\left(\mathrm{C}_{6} \mathrm{H}_{12}\right)$ & 5.00 & 0.29 & 1.00 \\
\hline Ethanol $\left(\mathrm{C}_{2} \mathrm{H}_{5} \mathrm{OH}\right)$ & 31.76 & 6.52 & 1.00 \\
\hline Ethylene $\left(\mathrm{C}_{2} \mathrm{H}_{4}\right)$ & 94.92 & 1.39 & 0.90 \\
\hline Formaldehyde $\left(\mathrm{CH}_{2} \mathrm{O}\right)$ & 6.69 & 0.47 & 0.83 \\
\hline Methane $\left(\mathrm{CH}_{4}\right)$ & 25.65 & 0.37 & 0.81 \\
\hline Pentane $\left(\mathrm{C}_{5} \mathrm{H}_{12}\right)$ & 235.37 & 10.64 & 0.98 \\
\hline Toluene $\left(\mathrm{C}_{7} \mathrm{H}_{8}\right)$ & 8.86 & 63.60 & 0.97 \\
\hline
\end{tabular}

Table S1: Estimated inlet composition process noise, FTIR measurement noise values and FTIR measurement centerburst weighting used within the UKF for each species. 
A.1 Quasi-Steady Maps

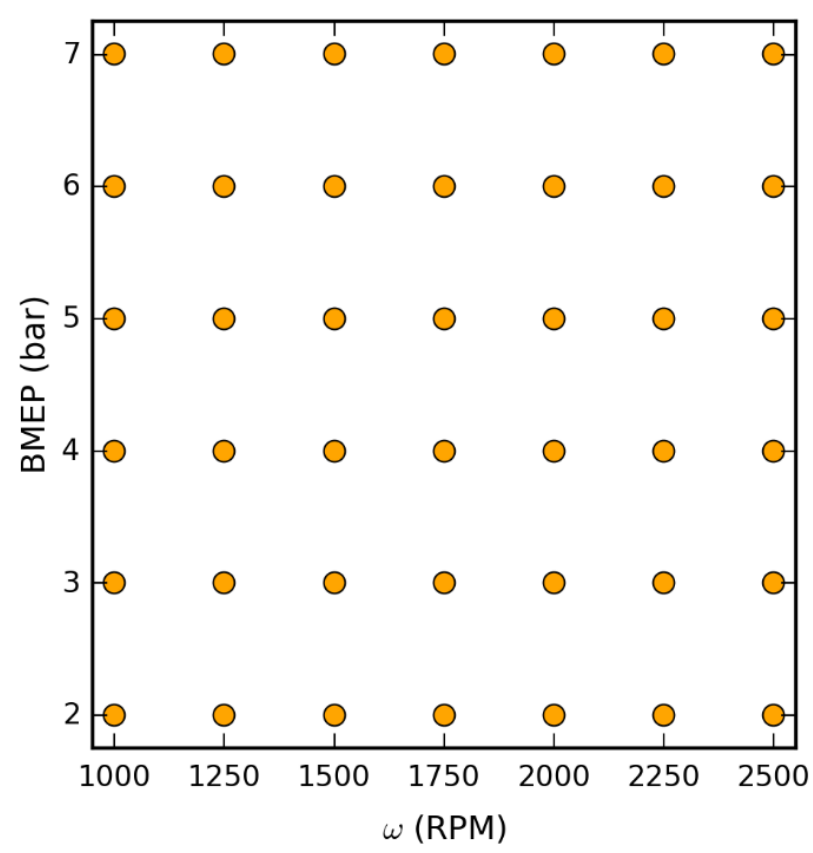

Figure S1: Speed/load points on the steady-state emissions map used to formulate the quasi-steady model. 
1,3 Butadiene

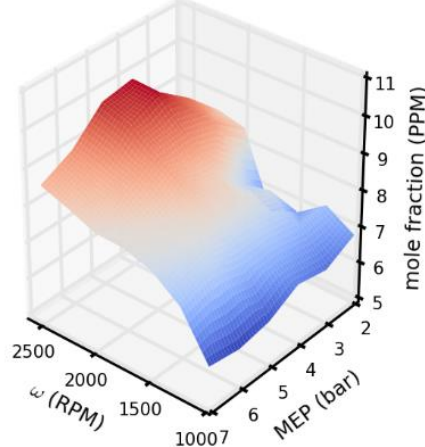

Ethane

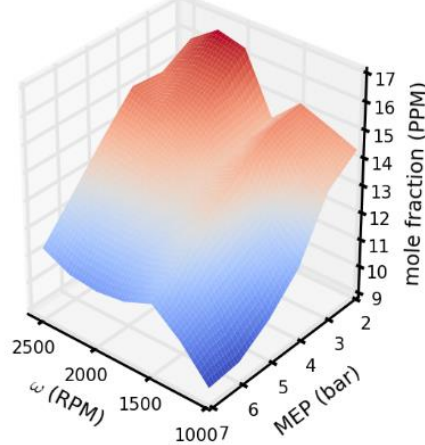

Formaldehyde

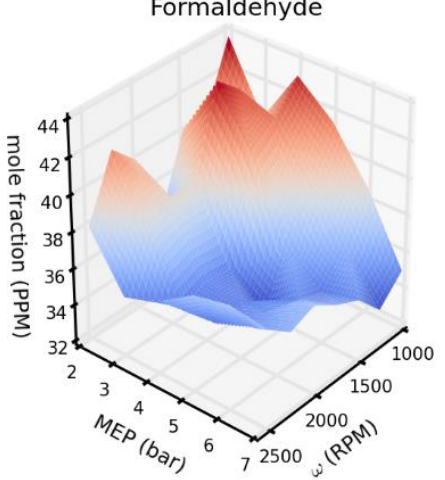

Acetylene

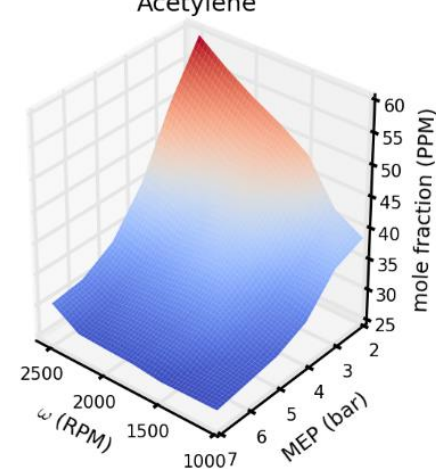

Ethanol

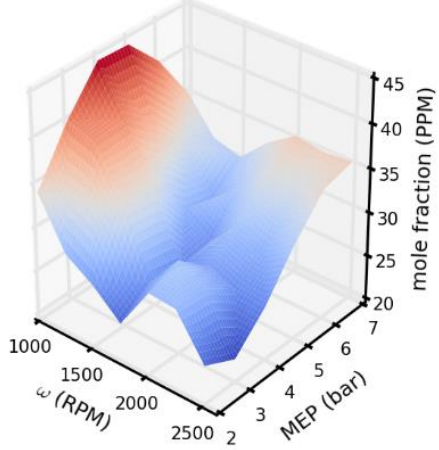

Methane

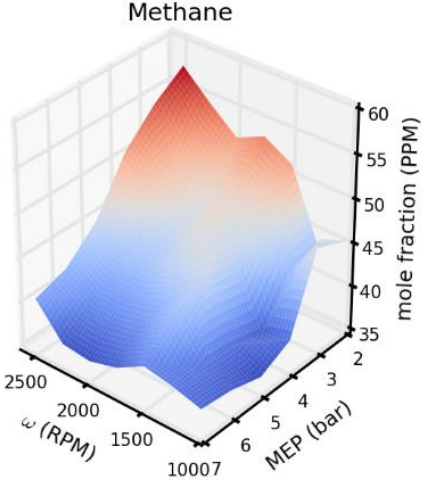

Cyclohexane

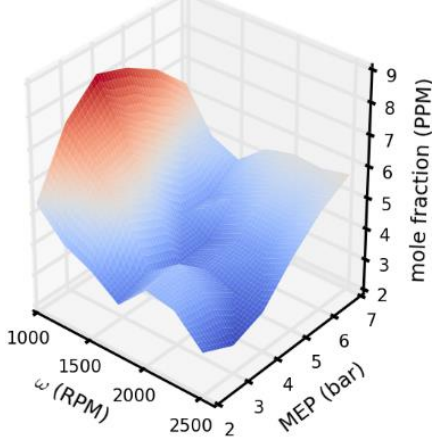

Ethylene

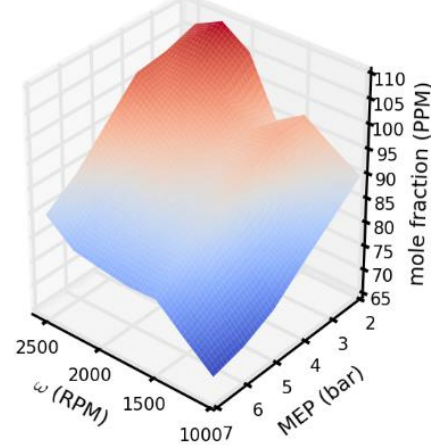

Pentane

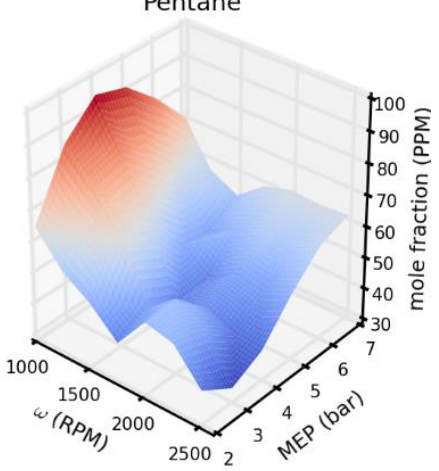

Figure S2: Steady-state emissions maps for each species with respect to engine speed and load. 
1,3 Butadiene

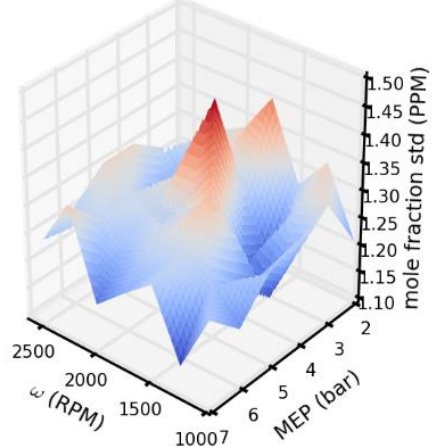

Ethane
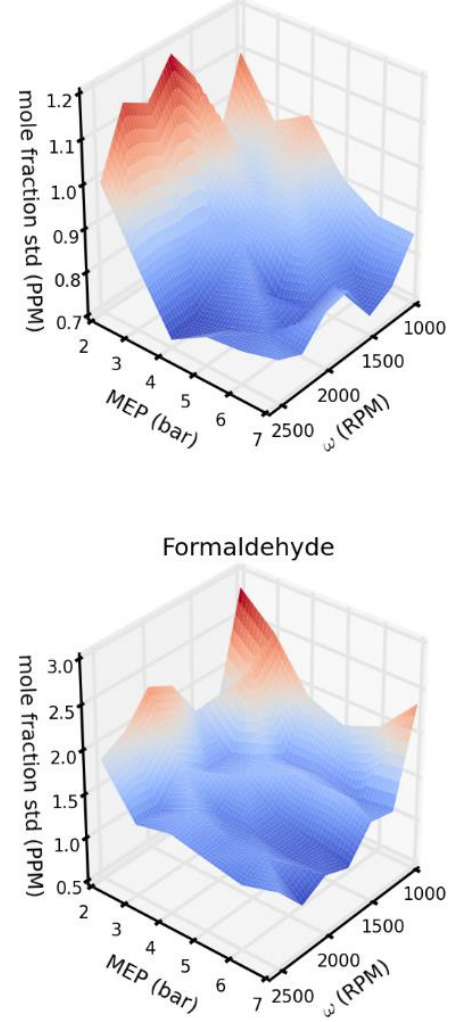

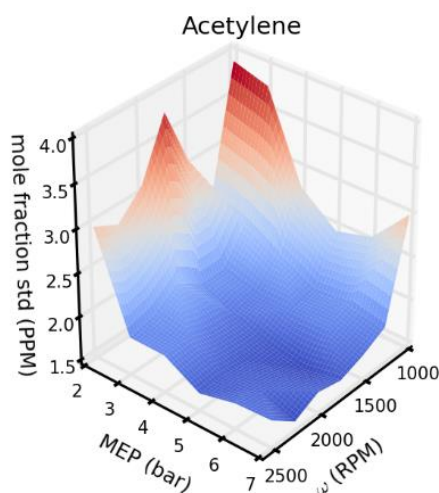

Ethanol
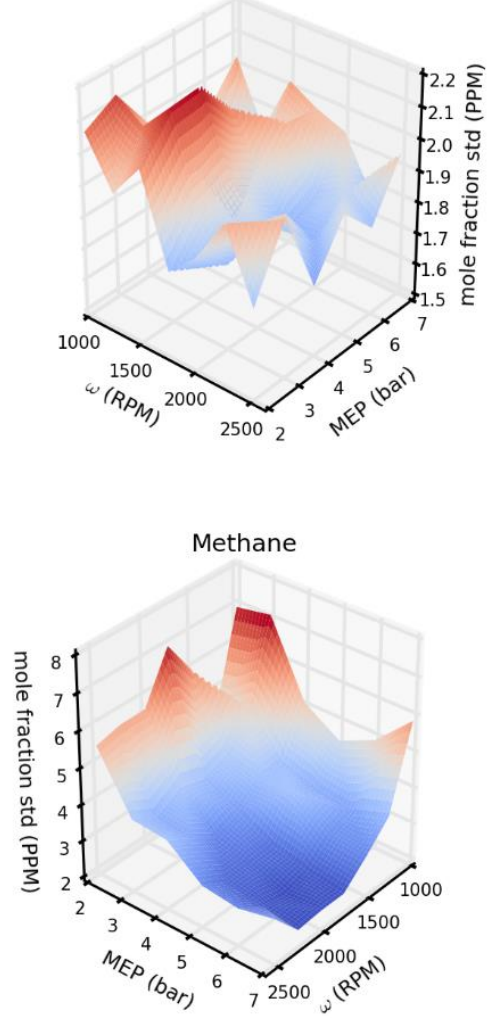

Cyclohexane

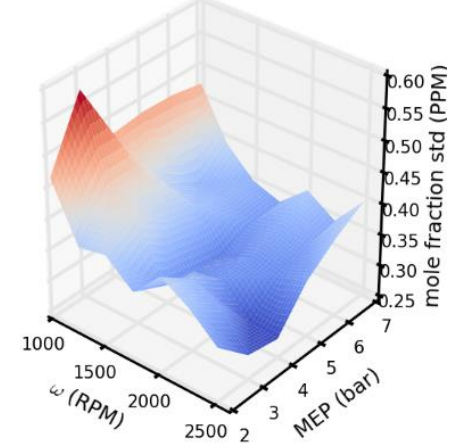

Ethylene

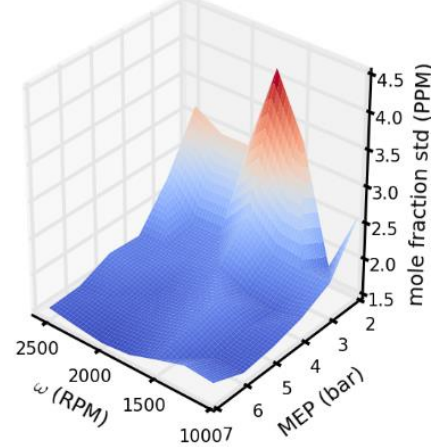

Pentane

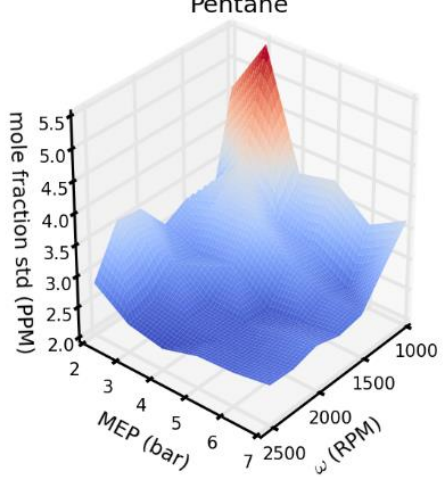

Figure S3: Map of estimated stochastic emissions fluctuation standard deviation for each species with respect to engine speed and load. 


\section{A.2 Emissions at 2000 RPM}

$$
-\mathrm{t}_{\mathrm{ramp}}=1 \mathrm{~s} \quad-\mathrm{t}_{\mathrm{ramp}}=2.5 \mathrm{~s} \quad-\mathrm{t}_{\mathrm{ramp}}=5 \mathrm{~s}
$$

Intermediates

a) Acetylene

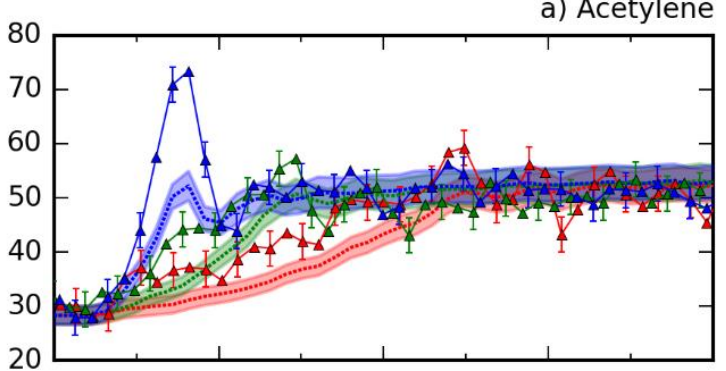

c) Ethylene

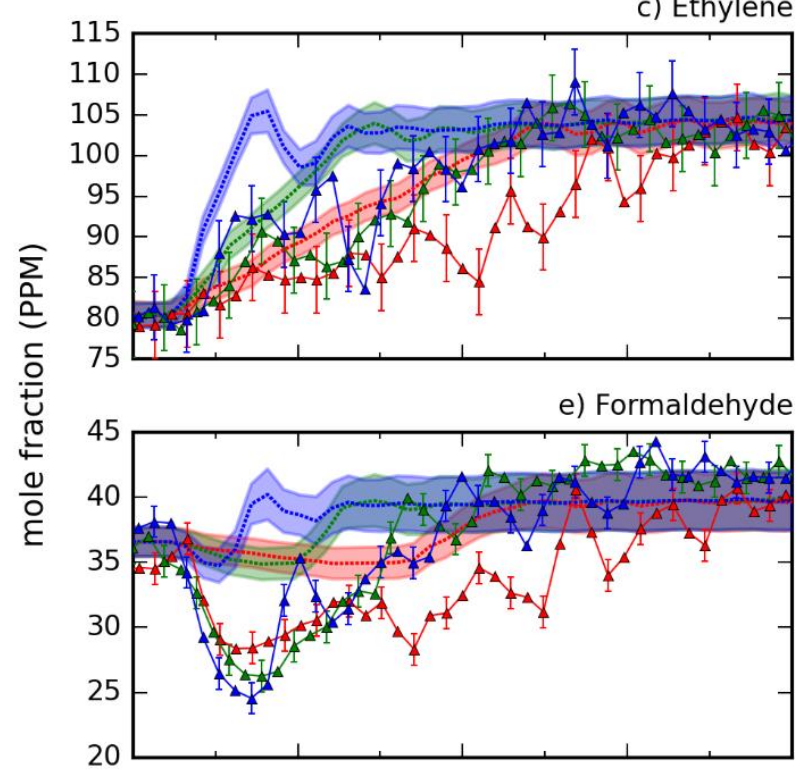

g) Methane

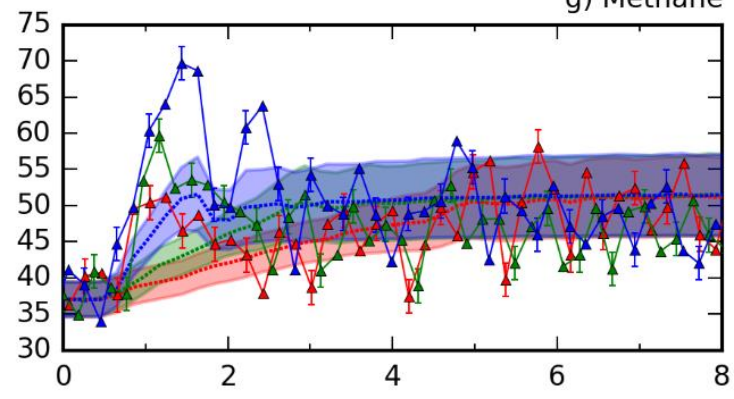

Fuel Components

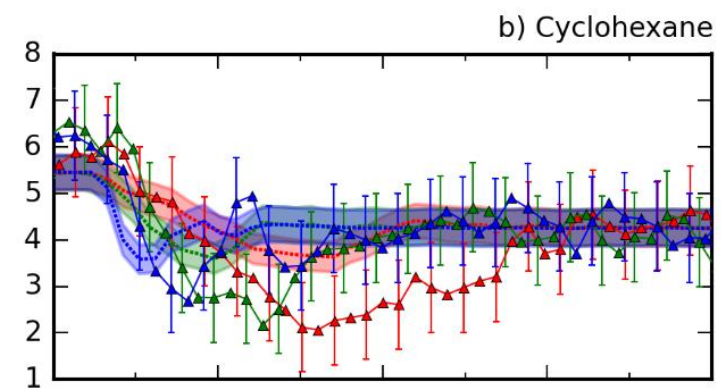

d) Ethanol
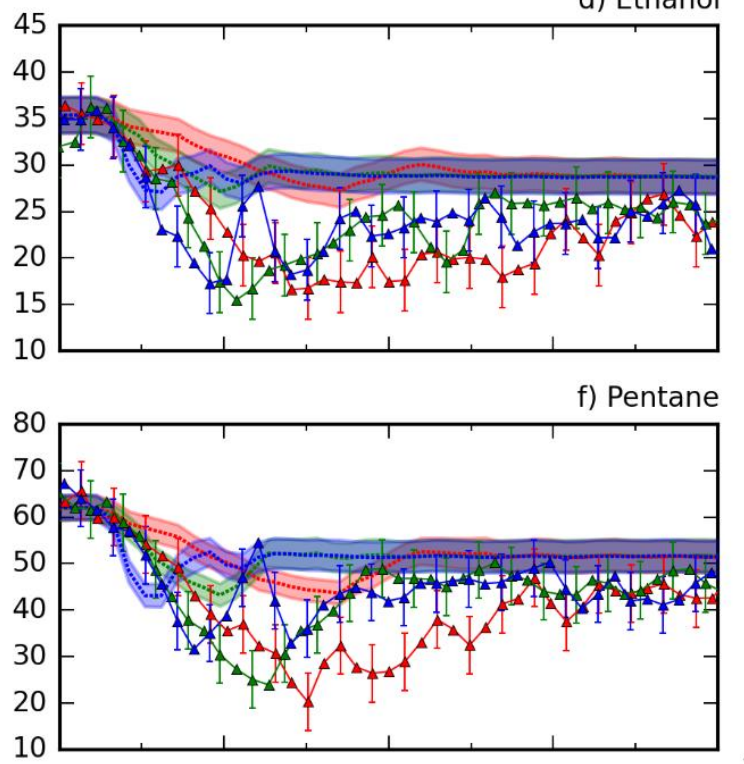

h)

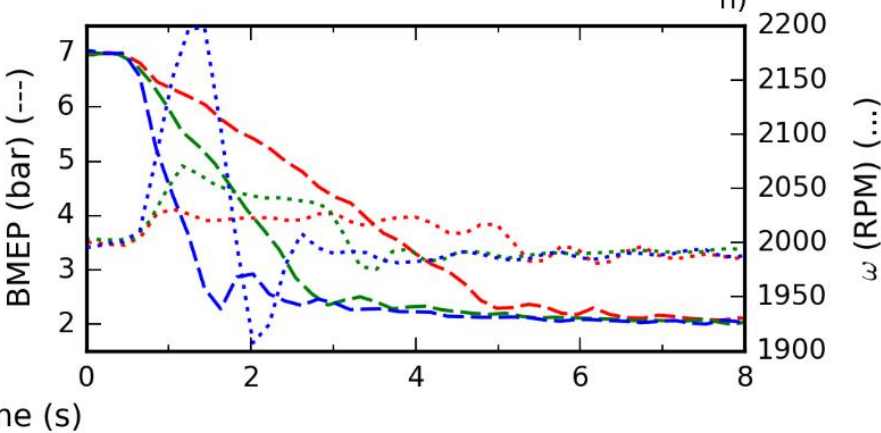

Figure S4: Emissions of various VOCs and engine speed/load for the negative load ramp, 2000 rpm cases. Error bars reflect the standard experimental emissions uncertainty, while the shaded area surrounding the quasi-steady predictions represents the estimated standard emissions stochasticity for the current engine speed/load. 


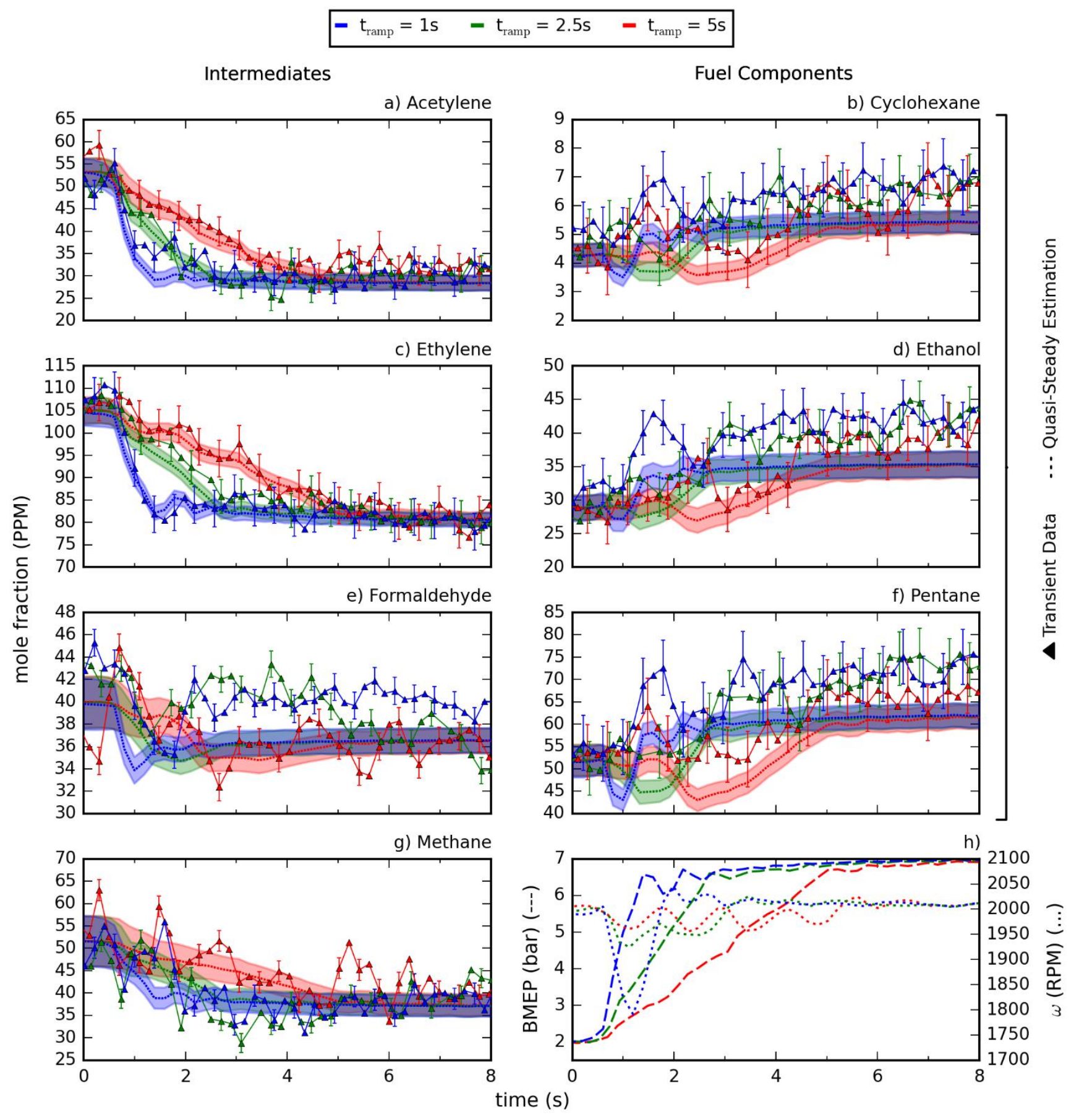

Figure S5: Emissions of various VOCs and engine speed/load for the positive load ramp, 2000 rpm cases. Error bars reflect the standard experimental emissions uncertainty, while the shaded area surrounding the quasi-steady predictions represents the estimated standard emissions stochasticity for the current engine speed/load. 


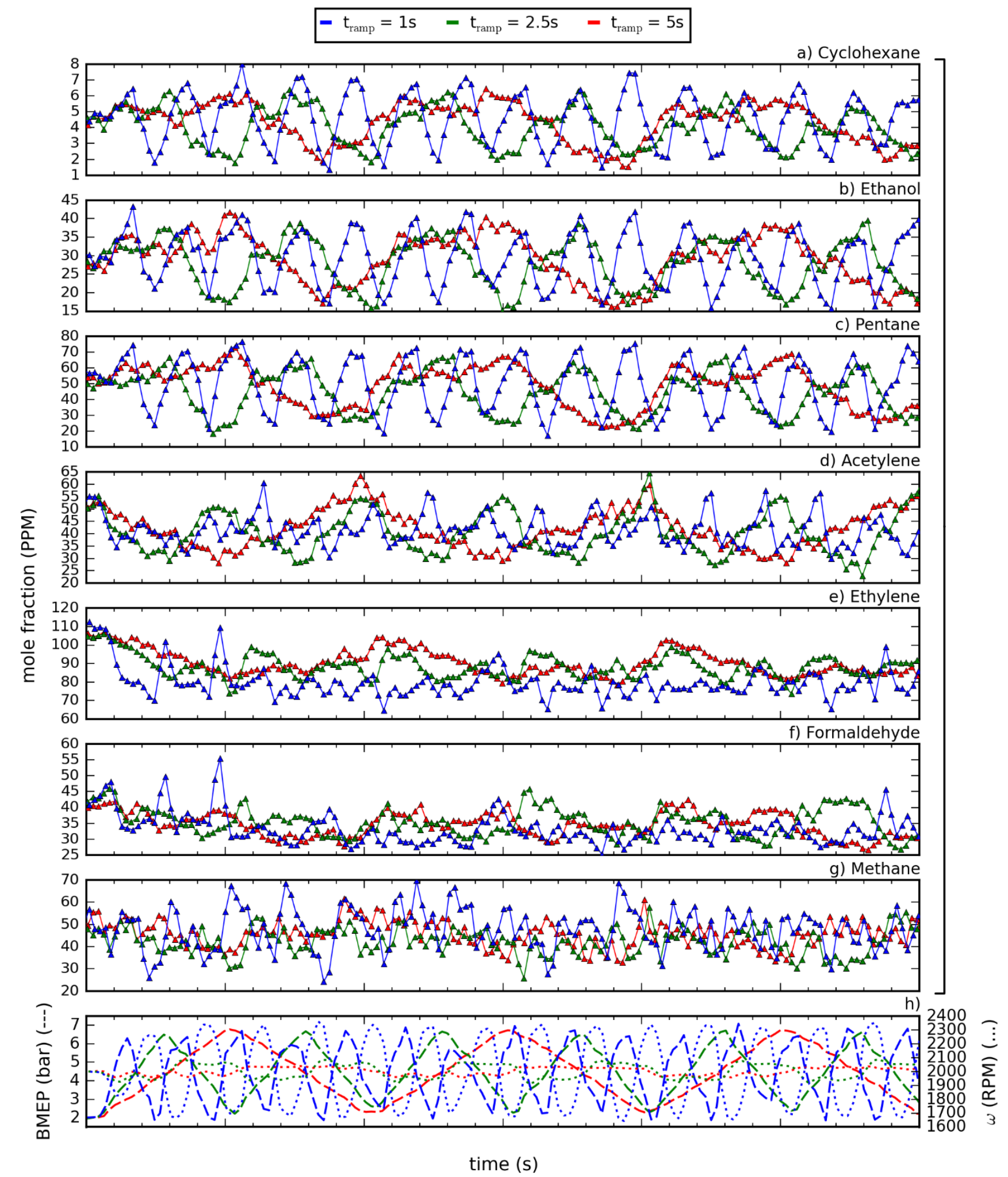

Figure S6: Emissions of various VOCs and engine speed/load for the periodic load profile, $2000 \mathrm{rpm}$ cases. 


\section{A.3 Repeatability}

To demonstrate the repeatability of some of the deterministic fluctuations identified in the experimental emissions, formaldehyde, pentane and ethylene emissions from both trials for each positive, negative and periodic load ramp case are presented in Figures S7-S9, respectively. Formaldehyde is chosen for this purpose as experimental formaldehyde emissions contain frequent fluctuations that contradict the quasi-steady model, some of which appear completely uncorrelated to engine conditions at first glance. Thus, repeatability improves confidence that these discrepancies are indeed deterministic and due to transient effects. Pentane and ethylene emissions are also chosen to demonstrate repeatability for an additional fuel component and intermediate species, respectively.

Repeatability in formaldehyde emissions is apparent in all the fluctuations near the onset of each load transient. For the positive, $1 \mathrm{~s}$ load ramp, the initial upward and downward oscillations for the two trials practically overlap one another, as do the initial emissions drops for the downward 1s load ramp. The spike near 2 seconds for the $5 s$ upward load ramp is also repeated in each trial, although the magnitudes of the spikes disagree by a few ppm. Even the intricate patterns in the 2.5 s periodic ramp profile are repeated, such as the brief uptick near 2 seconds. The only aspect where repeatability is not observed is in the timing at which long-term emissions fluctuations settle to their final, steady values. For example, the emissions profile for the $1 \mathrm{~s}$, upward load ramp begins descending toward its final value near 6 seconds for the first trial, while the emissions remain near 45 ppm past the 8 second window for the second trial. For pentane and ethylene, repeatability is also apparent for each load ramp, as the two trials display significant overlay and similarities in the timings and magnitudes of emissions fluctuations. The greatest discrepancies between the two trials occur at the onset of the negative, $1 \mathrm{~s}$ load ramps. For ethylene, the emissions fluctuations occur in opposite directions, while the upward spike in pentane emissions is $\sim 10 \mathrm{ppm}$ greater for the second trial compared to the first trial. Elevated fluctuation magnitudes for negative $1 \mathrm{~s}$ load ramps for the second trial are observed in acetylene and methane emissions as well (not shown). Regardless of these disparities, emissions from both trials deviate substantially from quasi-steady predictions (even more so in the second trial). Thus, data from both trials provide evidence that VOC emissions are influenced by transient operation. 


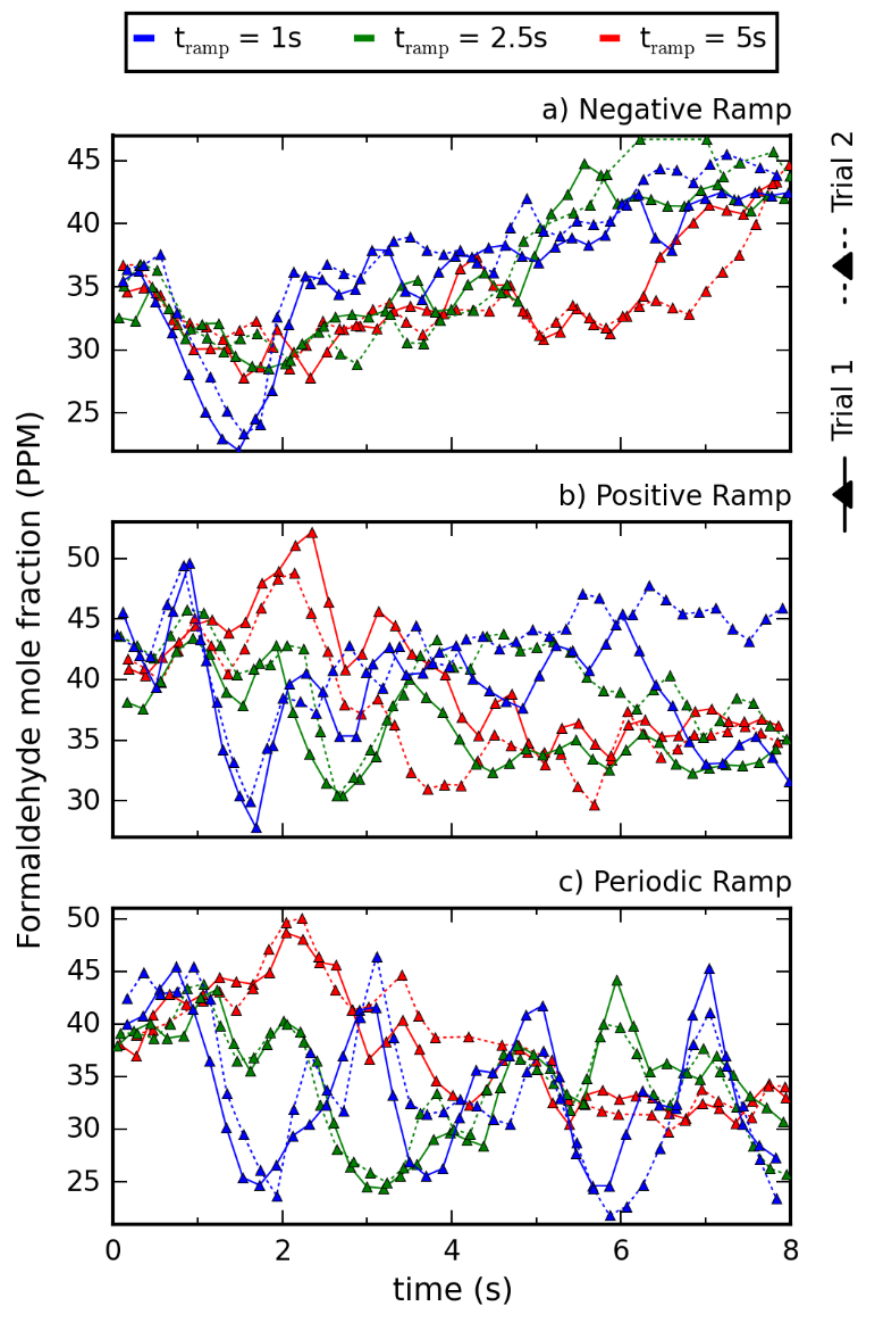

Figure S7: Emissions of formaldehyde from the first and second trials of the negative, positive and periodic load ramp, 1500 rpm cases. 


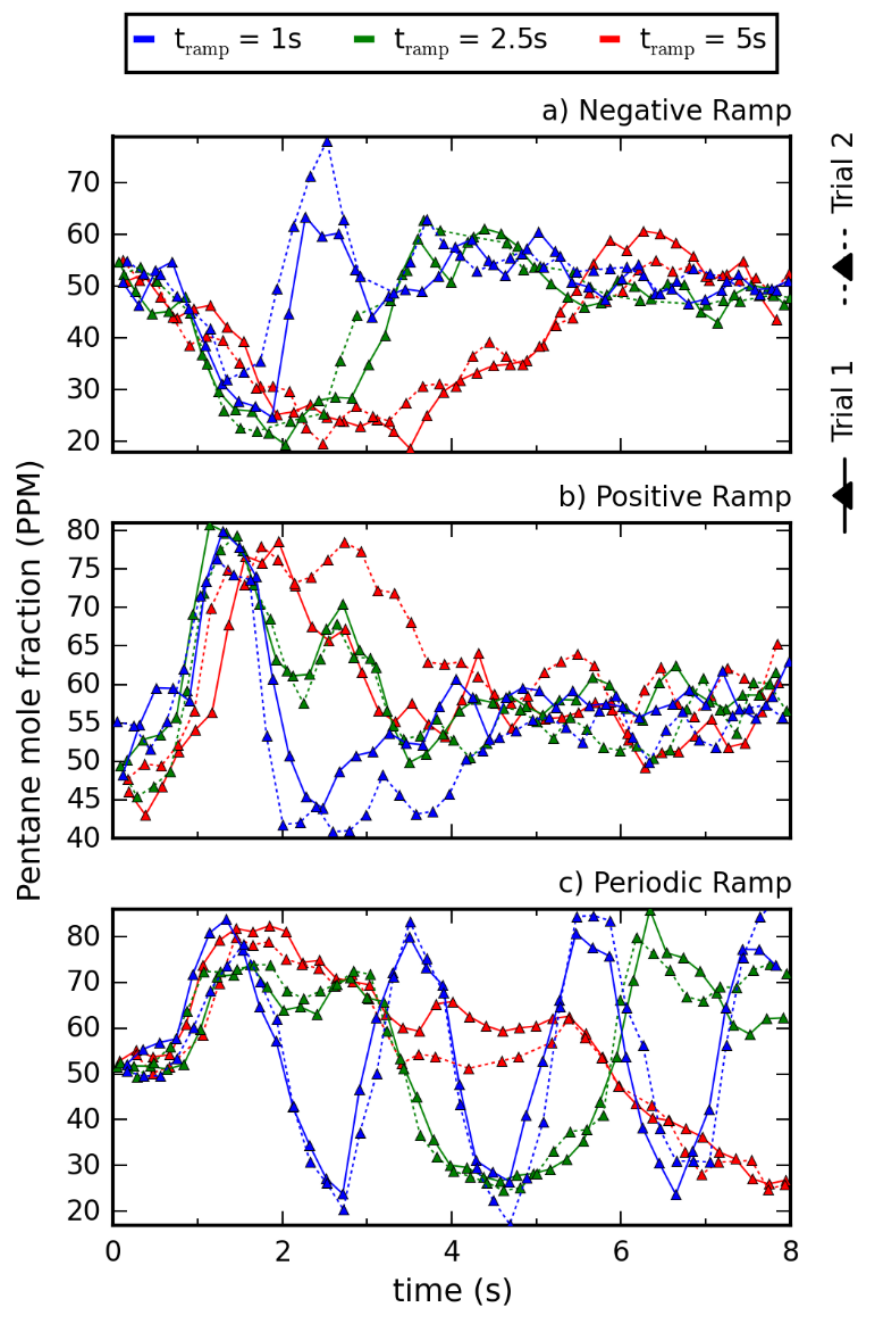

Figure S8: Emissions of pentane from the first and second trials of the negative, positive and periodic load ramp, 1500 rpm cases. 


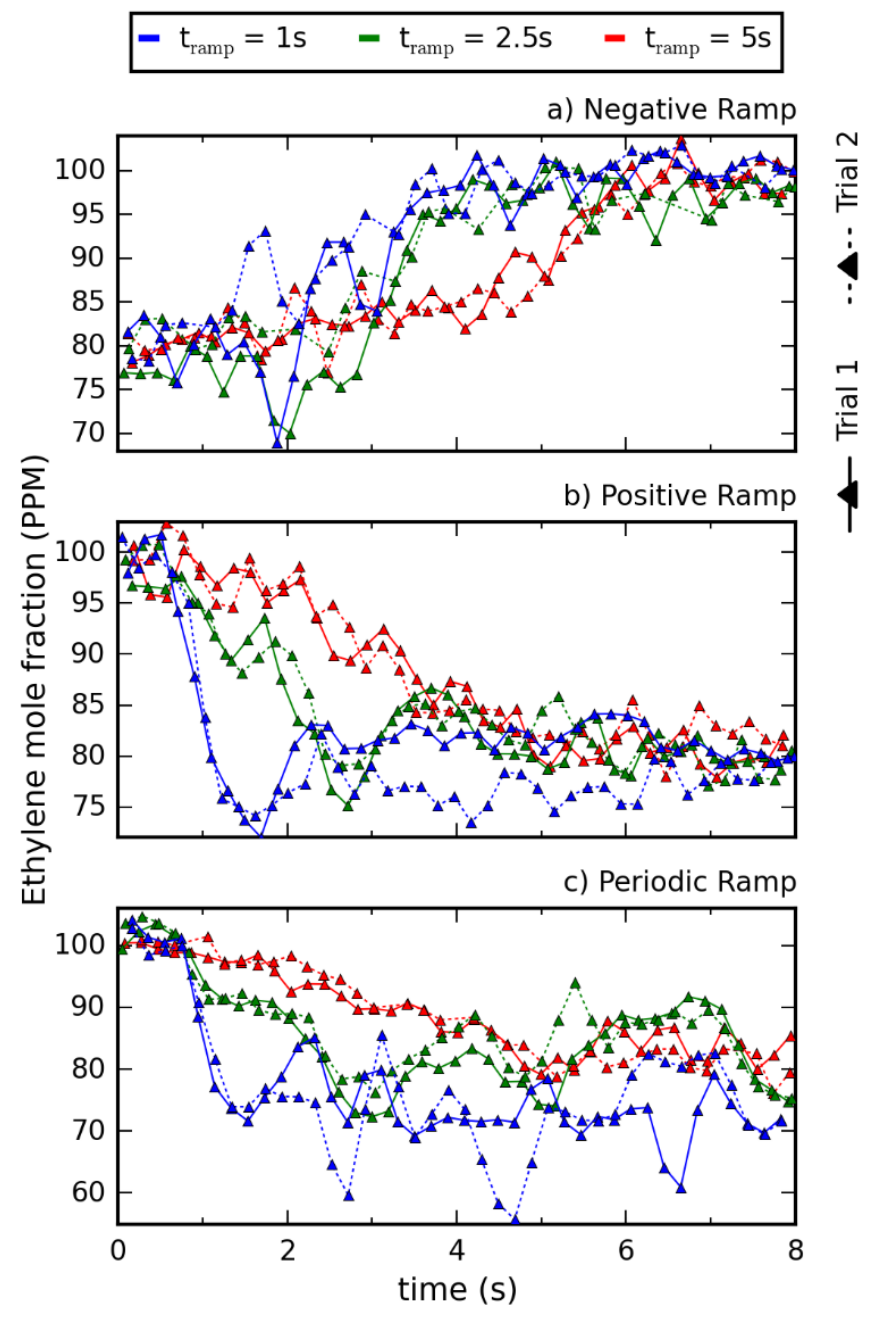

Figure S9: Emissions of ethylene from the first and second trials of the negative, positive and periodic load ramp, 1500 rpm cases. 


\section{A.4 Benzene and Toluene Emissions Measurement Noise}

As mentioned in the manuscript, the exacerbated noise of benzene and toluene species are caused by a combination of low absorptivity, low concentration, and the strong presence of highly interfering major combustion products. To illustrate this point, the analysis absorption spectra of toluene and benzene at 18.63 and $93.17 \mathrm{ppm}$ (the lowest calibrated compositions), respectively, are presented in Figure S10 along with the absorption spectra of carbon dioxide and water at typical compositions within combustion products. First, it is shown that moderate compositions of these species produce modest absorbances $(<<0.05)$ that are somewhat comparable to noise levels. To worsen the problem, the analysis spectra of these species are almost completely engulfed by the absorbance spectra of water and/or carbon dioxide. As absorbance increases in a spectral region, the power of the available signal diminishes, increasing the relative effects of noise. Thus, the presence of these major combustion products further reduces the fidelity of benzene and toluene measurements.

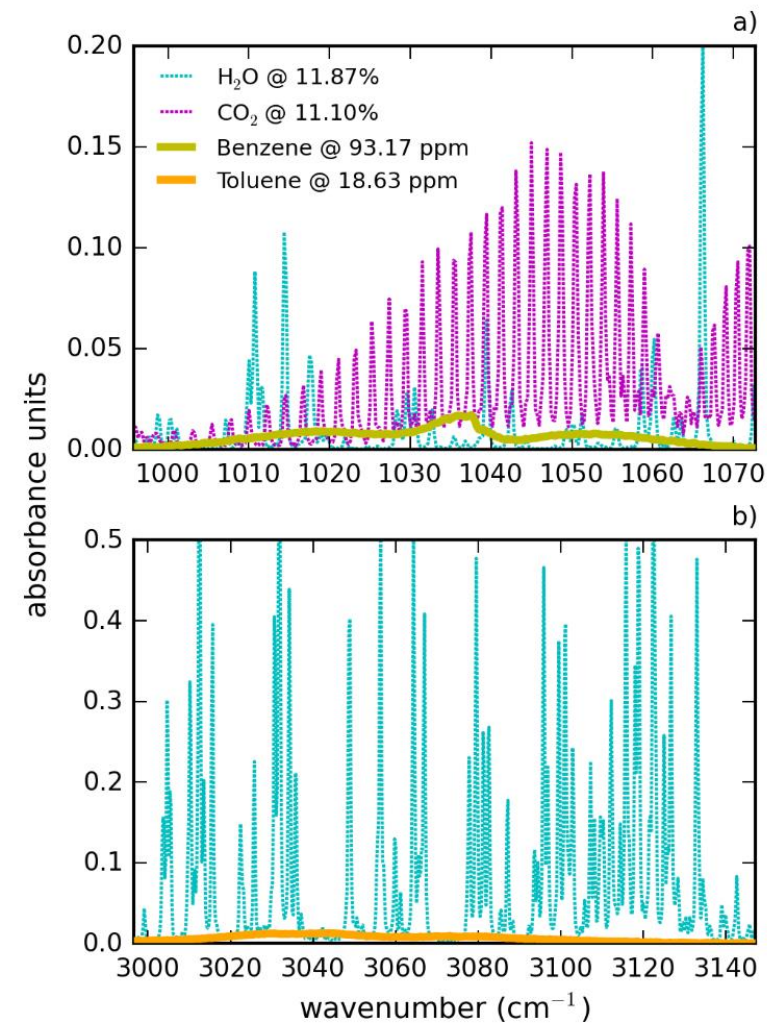

Figure S10: Calibrated spectral absorbances for a) benzene at a composition of $93.17 \mathrm{ppm}$ and b) toluene at a composition of 18.63 compared to absorbance spectrums of water and carbon dioxide at compositions that are typical within combustion products. 